\title{
Nicho ecológico e aspectos da história natural de Phyllomedusa azurea (Anura: Hylidae, Phyllomedusinae) no Cerrado do Brasil Central
}

\author{
Evellyn Borges de Freitas ${ }^{1}$, Crizanto Brito De-Carvalho ${ }^{1}$, Renato Gomes Faria ${ }^{1,5}$, \\ Renato de Carvalho Batista ${ }^{2}$, Cássio de Carvalho Batista ${ }^{2}$, \\ Welington Araújo Coelho ${ }^{3} \&$ Adriana Bocchiglieri ${ }^{4}$ \\ ${ }^{1}$ Departamento de Biologia, Universidade Federal de Sergipe - UFS, Cidade Universitária \\ Prof. Aloísio de Campos, Jardim Rosa Elze, CEP 49100-000, São Cristóvão, SE, Brasil \\ ${ }^{2}$ Faculdades Integradas da Terra de Brasília - FTB, \\ Av. Recanto das Emas, Quadra 203, Lote 31 S/N, CEP 72610-300, Brasília, DF, Brasil, www.ftb.edu.br \\ ${ }^{3}$ Campus I, Universidade Católica de Brasília - UCB, \\ Q.S. 07, Lote 01, Estrada Parque Contorno - EPCT, Águas Claras, CEP 71966-700, \\ Brasília, DF, Brasil, www.ucb.br \\ ${ }^{4}$ Departamento de Ecologia, Campus Darcy Ribeiro, Universidade de Brasília - UnB, \\ Asa Norte, CEP 70919-970, Brasília, DF, Brasil, www.unb.br \\ ${ }^{5}$ Autor para correspondência: Renato Gomes Faria, \\ e-mail: renatogfaria@ufs.br, renatogfaria@gmail.com,www.ufs.br
}

FREITAS, E.B., DE-CARVALHO, C.B., FARIA, R.G., BATISTA, R.C., BATISTA, C.C., COELHO, W.A. \& BOCCHIGLIERI, A. Ecological niche and aspects of the natural history of Phyllomedusa azurea (Anura: Hylidae, Phyllomedusinae) in the Cerrado of Central Brazil. Biota Neotrop. 8(4): http://www.biotaneotropica. org.br/v8n4/en/abstract?article+bn02108042008

\begin{abstract}
Aspects of the ecology and natural history of Phyllomedusa azurea were investigated in an area of Central Brazilian Cerrado between April, 2006, and February, 2007. Observations were conducted between 6:00 PM and 5:00 AM. The study focused on spatial, temporal, and trophic niches, morphometry and reproduction. Most animals were recorded vocalizing in places dominated by herbaceous vegetation and an open canopy. The main substrates used were bushes and trees, and animals were seen perched most often between 0.5 and $1.0 \mathrm{~m}$ of height. Spatial niche breadth was 2.91 and 3.83 for substrate and perch height, respectively. Most animal were sighted close to lentic water bodies, usually up to $0.50 \mathrm{~m}$. It is possible that these characteristics are related primarily to the phylogeny of the genus and secondarily to the specific needs of the species and the local availability of resources. The bushes and trees were used by the species mainly as sites of vocalization and oviposition. Specimens of Phyllomedusa azurea was sighted most frequently between 8:00 PM and 9:00 PM. Estimated temporal niche breadth (activity period) was 4.68. Prolonged reproductive pattern was also observed predominantly in the months with higher temperature and higher humidity (September to February). The diet consisted of eleven items. The most important prey taxon for the females was Orthoptera $(I V I=63)$, whereas for the males, it was Araneae $(I V I=$ 33). The breadths numeric and volumetric of the trophic niche, was respectively 1.80 and 1.16 , for females, and 4.03 and 3.92, for males. Males and females differed in size (SVL) and mass, with the females being larger and heavier. The sizes of smaller reproductive individuals males and females were 34.64 and $40.33 \mathrm{~mm}$, respectively. Differences in size may be related to different investments in reproduction by the two sexes.
\end{abstract}

Keywords: ecology, niche, habitat use, time activity, diet, sexual dimorphism.

FREITAS, E.B., DE-CARVAlHO, C.B., FARIA, R.G., BATISTA, R.C., BATISTA, C.C., COELHO, W.A., BOCCHIGLIERI, A. Nicho ecológico e aspectos da história natural de Phyllomedusa azurea (Anura: Hylidae, Phyllomedusinae) no Cerrado do Brasil Central. Biota Neotrop. 8(4): http://www.biotaneotropica.org.br/v8n4/ pt/abstract?article+bn02108042008

Resumo: Aspectos da ecologia e da história natural de Phyllomedusa azurea foram estudados em uma área de cerrado do Brasil Central, entre abril de 2006 e fevereiro de 2007. As observações foram realizadas entre as 18:00 e 5:00 h. Os aspectos investigados são referentes aos nichos espacial, temporal e trófico, morfometria e reprodução. A maioria dos animais vocalizou em locais com predominância do estrato herbáceo e de dossel aberto. Os principais substratos utilizados foram arbustos e árvores. Com relação às alturas de empoleiramento, os animais foram encontrados principalmente em locais entre 0,50 e 1,00 m de altura. As amplitudes de nicho espacial (substrato e altura de empoleiramento) foram respectivamente 2,91 e 3,83. A maioria dos animais foi encontrada próxima a corpos d'água lênticos, normalmente até $0,50 \mathrm{~m}$. É possível que essas características estejam primariamente relacionadas com a filogenia do gênero e secundariamente às necessidades particulares da espécie e à disponibilidade local de recursos. Os arbustos e árvores utilizados pela espécie servem como sítios de vocalização e ovoposição. Os espécimes de Phyllomedusa azurea foram localizados principalmente entre às 
Freitas, E.B. et al.

20:00 e 21:00 h. A largura de nicho temporal estimada (horário de atividade) foi de 4,68. Padrão reprodutivo prolongado foi também observado, predominando nos meses de maior temperatura e umidade (setembro a fevereiro). A dieta constituiu-se de 11 itens, sendo que o item mais importante para as fêmeas foi Orthoptera (IVI = 63) e para os machos Araneae (IVI = 43). As amplitudes numérica e volumétrica do nicho trófico foram respectivamente 1,80 e 1,16, para fêmeas, e 4,03 e 3,92, para machos. Machos e fêmeas diferiram em tamanho (CRC) e massa, com as fêmeas sendo maiores e mais pesadas. Os tamanhos dos menores indivíduos reprodutivos de machos e fêmeas foram 34,64 e 40,33 mm, respectivamente. Diferenças no tamanho podem estar relacionadas a distintos investimentos na reprodução pelos dois sexos.

Palavras-chave: ecologia, nicho, uso de habitat, horário de atividade, dieta.

\section{Introdução}

Phyllomeduza azurea Cope, 1862 foi recentemente revalidada sendo incluída no grupo de P. hypochondrialis (Caramaschi 2006). Está distribuída do leste da Bolívia, Paraguai até o norte da Argentina e em áreas de in uência das regiões do Pantanal e Cerrado no Brasil Central, ocorrendo nos estados de Mato Grosso, Mato Grosso do Sul, Tocantins, Goiás, Distrito Federal, Minas Gerais e no estado de São Paulo (Frost 2008, Prado et al. 2008). É uma espécie que possui porte médio para o grupo e, como outras espécies do gênero, deposita seus ovos na vegetação que margeia corpos d'água (Bastos et al. 2003, Caramaschi 2006).

O hábito de $P$. azurea é caracterizado como arborícola, possuindo adaptações morfológicas que beneficiam o mesmo, como o primeiro dedo da mão e o primeiro e segundo dos pés oponíveis aos demais (Caramaschi \& Cruz 2002, Caramaschi 2006) e, mesmo tendo a capacidade para saltar, os representantes deste gênero são normalmente observados caminhando lentamente sobre galhos e folhas em busca de alimento ou locais para repouso (Duellman \& Trueb 1994).

Informações sobre a dieta de $P$. azurea são muito escassas e baseadas em uma pequena amostra (Dure 1999). Os principais itens listados por esta autora para a área de Corrientes - Argentina de uma amostra de nove estômagos foram Diptera, Homoptera e Hymenoptera, respectivamente. Para o Cerrado não existe até o momento informações publicadas sobre a dieta desta espécie. Os modos de forrageamento e a composição da dieta em anuros são importantes fatores para a compreensão de suas interações ecológicas (Anderson \& Marthis 1999). Em geral os anfíbios são insetívoros, podendo também se alimentar de outros pequenos invertebrados (Eterovick \& Sazima 2004). A dieta está diretamente relacionada a aspectos morfológicos e fisiológicos que contribuem para a localização, identificação, captura e ingestão de uma ampla variedade de presas (Pough et al. 2004). A seleção de presas depende também de sua disponibilidade estacional, podendo variar em quantidade e qualidade ao longo do ano. Por isso, os anuros são considerados em geral, oportunistas na escolha de suas presas, estando suas dietas normalmente associadas às proporções das mesmas no ambiente em que vivem (Duellman $\&$ Trueb 1994).

Mesmo com o crescente número de trabalhos relacionados à ecologia de anfíbios nos últimos anos (e.g. Rodrigues et al. 2003, 2005, Silva et al. 2005, De-Carvalho et al. 2008, Lucas et al. 2008), há carência de informações básicas sobre a biologia da maior parte das espécies do Cerrado (Brites et al. in press). Poucas informações (e.g. Rodrigues et al. 2007, Prado et al. 2008) foram geradas para Phyllomedusa azurea desde sua revalidação por Caramaschi (2006). Dessa forma, com o presente estudo, buscamos aumentar o conhecimento sobre a biologia de P. azurea em área de Cerrado, no que diz respeito ao uso dos recursos espaciais, alimentares e temporais, sendo apresentadas também algumas informações sobre os aspectos reprodutivos dessa espécie.

\section{Material e Métodos}

Phyllomedusa azurea foi estudada em uma área de Cerrado pertencente à fazenda Porta do Céu (16 $13^{\prime} 50^{\prime}$ 'S e 48 $\left.04^{\prime} 49^{\prime \prime} \mathrm{W}\right)$, município de Novo Gama, GO. Com uma área de 582,3 ha, a fazenda mantém fitofisionomias típicas do Cerrado como matas de galeria, cerrado sensu strictu e campos em bom estado de conservação. $\mathrm{O}$ clima é sazonal com duas estações bem definidas: inverno seco que compreende o período de abril a setembro e verão chuvoso de outubro a março (Eiten 1972). A precipitação média anual fica entre 1.500 a $1.700 \mathrm{~mm}$ (Nimer 1989).

As coletas foram realizadas por duas pessoas, sendo adotadas duas noites consecutivas a cada semana entre os meses de abril de 2006 a fevereiro de 2007, totalizando 94 dias de campo. O método utilizado foi o de busca ativa (Crump \& Scott 1994), entre as 18:00 e 5:00 h em duas áreas brejosas, um fragmento de mata de galeria e três lagoas. Na primeira noite de cada semana foram vistoriadas duas lagoas e uma das áreas brejosas, e na segunda noite as demais áreas. Procurou-se manter esforços de coleta próximos para cada área estudada.

Os animais coletados foram acondicionados separadamente em sacos plásticos, cada um contendo uma etiqueta de identificação. No momento do encontro foram tomadas algumas informações como hábitat, se o animal estava em atividade de vocalização, horário, substrato utilizado, estrato predominante da vegetação (herbáceo, arbóreo, arbustivo, etc.), característica do dossel (aberto, intermediário ou fechado), altura de empoleiramento, distância até o corpo de água mais próximo e velocidade da água (corpo d'água lêntico ou lótico).

Depois de coletados, os animais foram sacrificados com injeção de lidocaína $2 \%$. A massa foi mensurada com o auxílio de um dinamômetro (precisão de 0,5 g) e 21 medidas (Figura 1) foram tomadas com um paquímetro digital (precisão de $0,01 \mathrm{~mm}$ ): CRC (comprimento rostro-cloacal); largura e altura do corpo; comprimento, largura e altura da cabeça; diâmetro do tímpano e do olho; distâncias interocular, olho-narina e inter-nasal; comprimentos e larguras do braço, antebraço, coxa e perna e comprimentos da mão e do pé. Todas as medidas de estruturas pares foram tomadas do lado direito do corpo do animal. Todos os animais coletados foram depositados na coleção Herpetológica da UNB (CHUNB).

Após serem medidos, os animais foram devidamente etiquetados, fixados em formalina 10\% e conservados em álcool 70\%. A condição reprodutiva (CR) dos animais foi verificada analisando-se as gônadas (fêmeas) e o saco vocal (machos), sendo atribuídas para cada sexo três classes: para as fêmeas, classe I - ovidutos desenovelados com tamanhos reduzidos e ovários pouco desenvolvidos, classe II - os ovidutos estão parcialmente enovelados e os ovários parcialmente desenvolvidos e classe III - os ovidutos são bastante enovelados e ovários bem desenvolvidos; para os machos, saco vocal reduzido (SVR) - não desenvolvido, intermediário (SVI) - parcialmente 


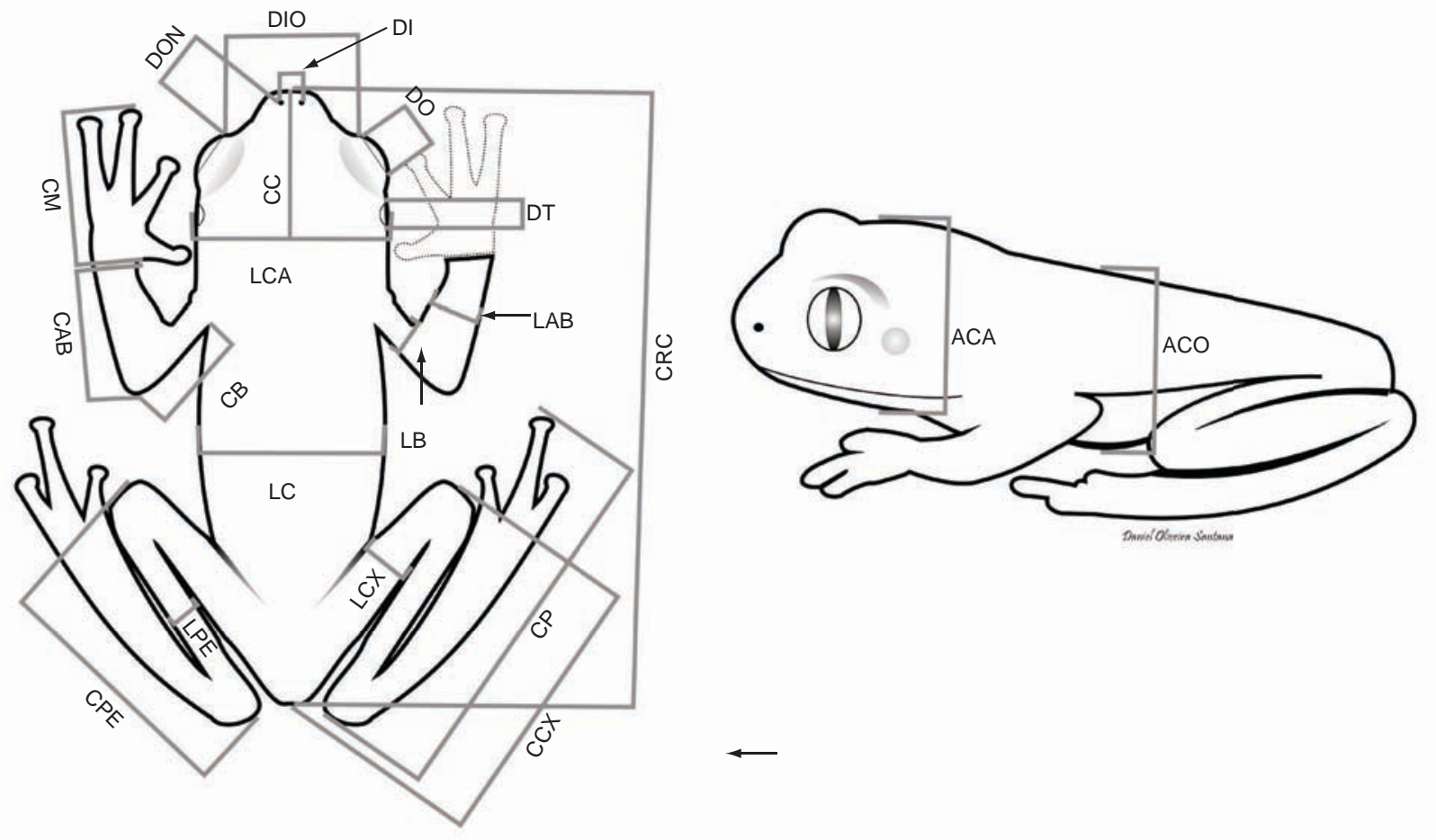

Figura 1. Características morfológicas de Phyllomedusa azurea do município de Novo Gama, GO, Brasil. CC, comprimento da cabeça; ACA, altura da cabeça; LCA, largura da cabeça; DON, distância olho-narina; DIO, distância interocular; DO, diâmetro do olho; DI, distância internasal; DT, Diâmetro do tímpano; CRC, comprimento rostro-cloacal; ACO, altura do corpo; LC, largura do corpo; LB, largura do braço; CB, comprimento do braço; LAB, largura do ante-braço; $\mathrm{CAB}$, comprimento do ante-braço; CM, comprimento da mão; LCX, largura da coxa; CCX, comprimento da coxa; LPE, largura da perna; CPE, comprimento da perna; $\mathrm{CP}$, comprimento do pé.

Figure 1. Morphological characteristics for Phyllomedusa azurea from the municipality of Novo Gama, GO, Brazil. CC, head length; ACA, head height; ACL, head width; DON, eye-nostril distance; DIO, interocular distance, DO, eye diameter; DI, internasal distance; DT, tympanum diameter; CRC, snout-vent length; ACO, body height; LC, body width, LB, arm width, CB, arm length; LAB, forearm width; CAB, forearm length, CM, hand length; LCX, thigh width; CCX, thigh length; LPE, leg width; CPE, leg length; CP, foot length.

desenvolvido e evidente (SVE) - bem desenvolvido. Os animais considerados potencialmente reprodutivos foram os de classe III (fêmeas) e SVE (machos) (Mesquita et al. 2004).

Em laboratório, os estômagos foram retirados e abertos e os seus conteúdos analisados sob microscópio estereoscópico. Os itens encontrados foram identificados com o auxílio de bibliografia especializada (Buzzi 2002), até o nível de ordem. As presas foram contadas e, aquelas encontradas inteiras, medidas com paquímetro, quanto ao maior comprimento e largura, para estimar seus volumes através da fórmula do volume do elipsóide (Magnusson et al. 2003):

Volume $=\left(\pi\right.$.comprimento.largura $\left.{ }^{2}\right) / 6$

Um índice de valor de importância (IVI) foi calculado para verificar o quanto cada item alimentar participa na dieta de Phyllomedusa azurea, através da seguinte equação (Gadsden \& Palácios-Orona 1997):

$$
\mathrm{IVI}=(\mathrm{N} \%+\mathrm{V} \%) / 2
$$

onde $\mathrm{N}$ é o número e $\mathrm{V}$ o volume de presas em cada categoria de item alimentar, todos em porcentagem.

As amplitudes de nicho alimentar $(B)$ para machos e fêmeas foram calculadas separadamente utilizando o índice de diversidade de Simpson (1949). O mesmo índice foi adotado no cálculo das amplitudes de nicho espacial (hábitat, substrato e altura de empoleiramento) e temporal (períodos do ano e horários) e, nestes casos, os dados de machos e fêmeas foram agrupados.

Todas as variáveis morfométricas e as dimensões das presas foram $\log _{10}$ - transformadas para aproximar a amostra de uma distribuição normal e reduzir os efeitos de escala. Variáveis tamanho-ajustadas (resíduos) foram geradas por meio de regressões lineares simples entre o CRC e cada variável tomada. Diferenças no tamanho e na forma de machos e fêmeas de $P$. azurea foram inicialmente investigadas por uma análise de componentes principais (ACP) das variáveis tamanho-ajustadas (Tabachnick \& Fidell 2000). Os tamanhos dos corpos (CRC) foram então comparados entre os sexos por análise de variância (ANOVA) e a massa por análise de covariância (ANCOVA), tomando por co-variável o CRC.

As proporções numéricas e volumétricas com que as categorias de presas foram utilizadas por cada sexo foram comparadas pelo teste de Kolmogorov-Smirnov e a preferência por locais com corpos d'água lênticos ou lóticos pelo teste de G com correção de Yates (Ayres et al. 2007). A análise de Correlação Canônica entre dois grupos de variáveis (comprimento e largura máximos de presas vs. comprimento, largura e altura da cabeça) foi aplicada para investigar as relações entre as dimensões das presas e as medidas da cabeça. Diferenças intersexuais com relação à posição vertical (altura de empoleiramento) 
e distância do corpo d'água mais próximo foram testadas por análise de variância (ANOVA) (Zar 1999, Hill \& Lewicki 2007).

As análises estatísticas foram realizadas nos softwares Systat 12.0 (Wilkinson 1990) e BioEstat 5.0 (Ayres et al. 2007), com nível de significância de $5 \%$.

\section{Resultados}

Foram coletados 56 espécimes de Phyllomedusa azurea (48 machos e 8 fêmeas). Um resumo dos dados morfométricos está disponível na Tabela 1. Machos e fêmeas diferiram em tamanho (CRC) $\left(\mathrm{F}_{1,54}=51,543, \mathrm{P}<0,0001, \mathrm{~N}=56\right)$ e massa (ANCOVA, $\mathrm{F}_{1,53}=27,060, \mathrm{P}<0,0001, \mathrm{~N}=56$ ), com as fêmeas sendo maiores e mais pesadas (Tabela 1). Os resultados da análise dos componentes principais (ACP) mostraram diferenças adicionais (Tabela 2, Figura 2), porém os dois primeiros componentes acumularam menos de $40 \%$ da variação da análise. O primeiro componente principal está relacionado com a largura do antebraço, da perna e da cabeça (Tabela 2). Já o segundo componente relaciona-se com o comprimento do pé e da coxa (Tabelas 1 e 2; Figura 2).

Phyllomedusa azurea foi encontrada principalmente em área brejosa (91\%) com predomínio do estrato herbáceo (91\%) e com característica de dossel aberto $(61 \%)$. Os substratos mais utilizados foram arbustos (45\%) e árvores (34\%), onde foram observadas desde o solo até 2,5 m de altura, com predominância entre 0,5 e 1,0 m (39\%) (Figura 3). Não foram verificas diferenças entre as alturas de empoleiramento adotadas por cada um dos sexos (ANOVA, $F_{1,52}=0,441$,
$\mathrm{P}=0,509, \mathrm{~N}=56)$ e nem para as distâncias até os corpos d'água mais próximos (ANOVA, $\mathrm{F}_{1,54}=0,252, \mathrm{P}=0,617, \mathrm{~N}=56$ ). Os espécimes foram observados em locais que normalmente não excediam 5,0 m do corpo d'água mais próximo, sendo mais comuns em locais com até $0,50 \mathrm{~m}$ da margem (Figura 4). Quanto à velocidade da água nas proximidades em que os animais foram encontrados, $79 \%$ dos indivíduos foram observados em locais com corpos d'água lênticos. Machos e fêmeas não diferem com relação à ocupação de ambientes lênticos ou lóticos $(\mathrm{G}=0,6748$, g.l. $=1, \mathrm{P}=0,4114)$ (Figura 5). A amplitude do nicho espacial referente ao tipo de hábitat, substrato e altura de empoleiramento foram respectivamente: 1,$20 ; 2,91$ e 3,83 .

Os indivíduos foram observados entre os meses de setembro de 2006 a fevereiro de 2007, sendo mais freqüentes nos meses de setembro e outubro, cujas médias de precipitação foram de 40,3 e $526,4 \mathrm{~mm}$, de umidade relativa 49 e $80 \%$ e de temperatura 20 e $21.2^{\circ} \mathrm{C}$, respectivamente (Figura 6). Os horários de encontro variaram das 19:50 às 4:20 h, sendo mais freqüentes entre as 20:00 e 21:00 h (36\%; Figura 7). As amplitudes de nicho temporal estimadas para períodos do ano e horários foram 4,68 e 4,92, respectivamente. Dos 56 espécimes coletados $54 \%$ estavam vocalizando, $32 \%$ parados e $8 \%$ em amplexo.

Foram analisados 56 estômagos de $P$. azurea (48 machos e oito fêmeas) dos quais cinco estavam vazios e quatro em processo avançado de digestão. Os espécimes utilizaram 11 categorias de itens alimentares, tendo sido verificado também material vegetal e detritos, que consistiram de pequenos grânulos de minerais como

Tabela 1. Medidas morfométricas de machos e fêmeas de Phyllomedusa azurea do município de Novo Gama, GO, Brasil. Medidas lineares são apresentadas em milímetros (mm) e a massa em gramas $(\mathrm{g})$.

Table 1. Morphometric measurements of male and female of Phyllomedusa azurea from the municipality of Novo Gama, GO, Brazil. Linear measurements are given in millimeters $(\mathrm{mm})$ and weight in grams $(\mathrm{g})$.

\begin{tabular}{|c|c|c|c|c|}
\hline \multirow[t]{3}{*}{ Medidas morfométricas } & \multicolumn{4}{|c|}{ Phyllomedusa azurea $(N=56)$} \\
\hline & \multicolumn{2}{|c|}{$\operatorname{Machos}(\mathbf{N}=48)$} & \multicolumn{2}{|c|}{ Fêmeas $(\mathbf{N}=\mathbf{8})$} \\
\hline & $\overline{\mathbf{x}} \pm \mathbf{d p}$ & $\min -m a x$ & $\overline{\mathbf{x}} \pm \mathbf{d p}$ & min-max \\
\hline Massa & $2,49 \pm 0,41$ & $1,80-3,70$ & $4,49 \pm 0,74$ & $3,80-6,00$ \\
\hline Comprimento rosto-cloacal & $36,45 \pm 2,06$ & $32,99-41,70$ & $42,33 \pm 1,85$ & $39,56-44,67$ \\
\hline Largura do corpo & $7,99 \pm 2,26$ & $2,77-13,59$ & $13,68 \pm 3,17$ & $7,55-17,54$ \\
\hline Altura do corpo & $6,53 \pm 1,23$ & $3,74-9,05$ & $8,64 \pm 2,19$ & $6,10-11,87$ \\
\hline Comprimento da cabeça & $13,00 \pm 1,92$ & $3,29-16,70$ & $14,88 \pm 1,54$ & $12,59-16,84$ \\
\hline Largura da cabeça & $10,71 \pm 1,06$ & $7,24-14,11$ & $11,98 \pm 0,46$ & $11,20-12,45$ \\
\hline Altura da cabeça & $6,74 \pm 1,54$ & $3,95-12,06$ & $6,92 \pm 1,21$ & $4,92-8,56$ \\
\hline Diâmetro do tímpano & $1,86 \pm 0,36$ & $1,02-2,75$ & $2,14 \pm 0,40$ & $1,48-2,88$ \\
\hline Distância interocular & $5,99 \pm 0,90$ & $1,49-7,43$ & $7,20 \pm 0,54$ & $6,52-8,13$ \\
\hline Distância olho-narina & $2,59 \pm 0,31$ & $1,76-3,31$ & $3,02 \pm 0,24$ & $2,61-3,33$ \\
\hline Diâmetro do olho & $3,73 \pm 0,68$ & $1,44-5,29$ & $4,09 \pm 0,65$ & $3,23-4,84$ \\
\hline Distância internasal & $3,16 \pm 0,36$ & $2,25-3,83$ & $3,45 \pm 0,40$ & $2,62-3,80$ \\
\hline Comprimento do braço & $7,86 \pm 1,29$ & $2,64-9,61$ & $9,40 \pm 1,02$ & $7,66-10,66$ \\
\hline Largura do braço & $1,65 \pm 0,36$ & $0,90-2,60$ & $1,56 \pm 0,38$ & $1,02-2,11$ \\
\hline Comprimento do antebraço & $8,99 \pm 0,79$ & $7,22-10,53$ & $10,47 \pm 0,67$ & $9,65-11,79$ \\
\hline Largura do antebraço & $2,50 \pm 0,54$ & $1,04-3,80$ & $2,37 \pm 0,49$ & $1,27-2,83$ \\
\hline Comprimento da mão & $8,52 \pm 1,24$ & $2,24-10,51$ & $9,61 \pm 0,75$ & $8,56-10,68$ \\
\hline Comprimento da coxa & $12,49 \pm 1,50$ & $9,36-15,75$ & $14,42 \pm 0,82$ & $13,39-15,80$ \\
\hline Largura da coxa & $3,22 \pm 0,73$ & $1,36-4,90$ & $3,47 \pm 0,67$ & $2,09-4,22$ \\
\hline Comprimento da perna & $14,05 \pm 1,35$ & $10,29-17,09$ & $16,45 \pm 1,26$ & $14,45-17,62$ \\
\hline Largura da perna & $2,48 \pm 0,54$ & $1,11-3,39$ & $2,89 \pm 0,37$ & $2,38-3,43$ \\
\hline Comprimento do pé & $22,01 \pm 1,39$ & $18,29-25,14$ & $24,03 \pm 1,13$ & $21,78-25,53$ \\
\hline
\end{tabular}




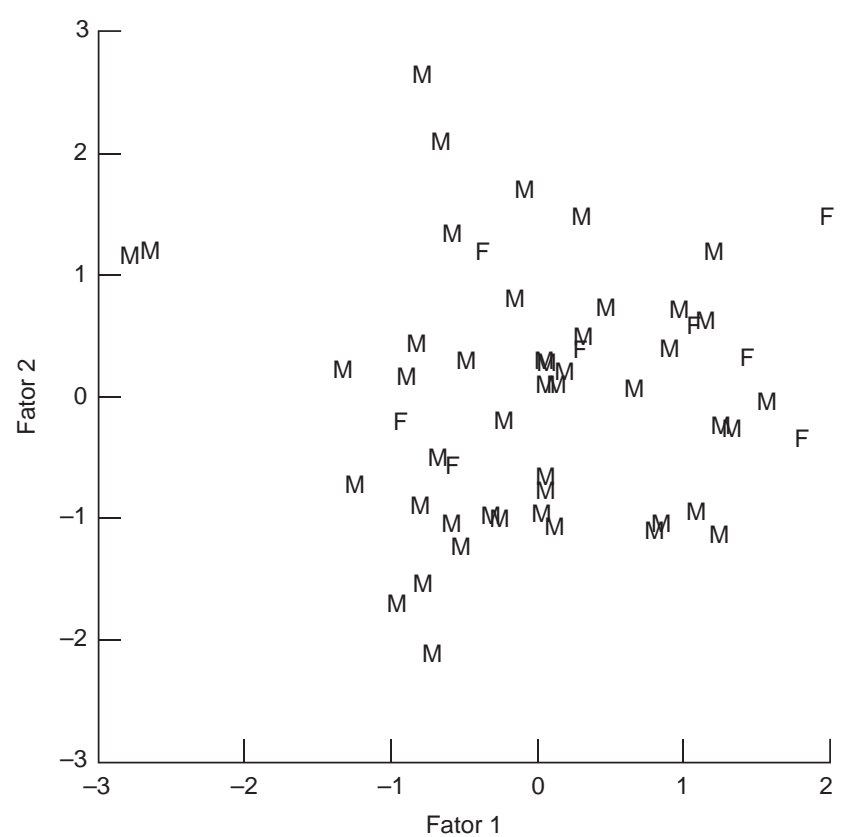

Figura 2. Escores dos fatores para CPI e CPII das variáveis morfológicas tamanho ajustadas para machos (M) e fêmeas(F) de Phyllomedusa azurea do município de Novo Gama, GO, Brasil.

Figure 2. The PC I and PC II factor scores for the size-adjusted morphological variables for male (M) and female (F) for Phyllomedusa azurea from the municipality of Novo Gama, GO, Brazil.

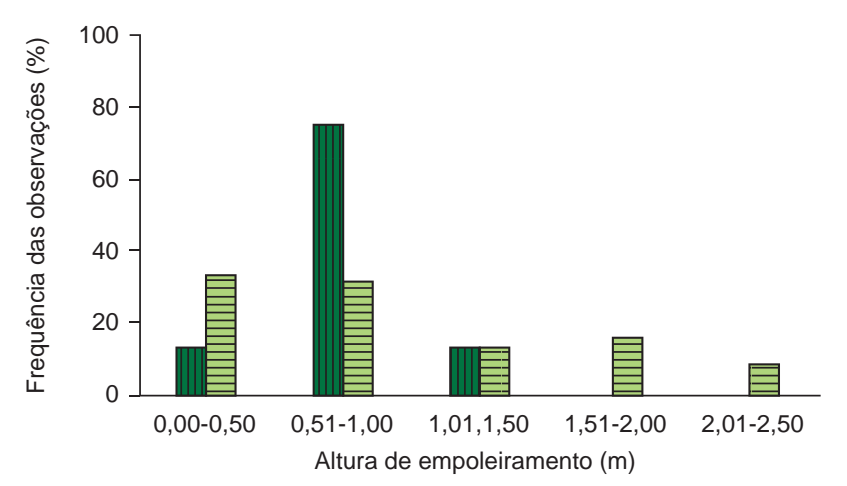

Fêmeas $\boxminus$ Machos

Figura 3. Frequência relativa das observações de machos e fêmeas de Phyllomedusa azurea com relação à altura de empoleiramento na vegetação, no município de Novo Gama, GO, Brasil.

Figure 3. Relative frequency of observations of male and female of Phyllomedusa azurea in relation to perch height on the vegetation from the municipality of Novo Gama, GO, Brazil.

areia e pedras (Tabela 3). A dieta de machos e fêmeas constituiu-se respectivamente de 11 e três categorias de itens alimentares (Tabela 3 ). As categorias mais frequientes foram, para os machos, material vegetal $(38 \%)$ e Araneae $(25 \%)$ e, para as fêmeas, material vegetal $(75 \%)$, Hymenoptera e Orthoptera (ambos com 13\%) (Tabela 3).

Foram observadas diferenças significativas nas proporções numéricas em que as categorias de presas foram utilizadas por machos $(\mathrm{m})$ e fêmeas $(f)$ (Kolmogorv-Smirnov, $\mathrm{D}_{\max }=0,7677$, g.l. $=2, \mathrm{P}<0,0001$;

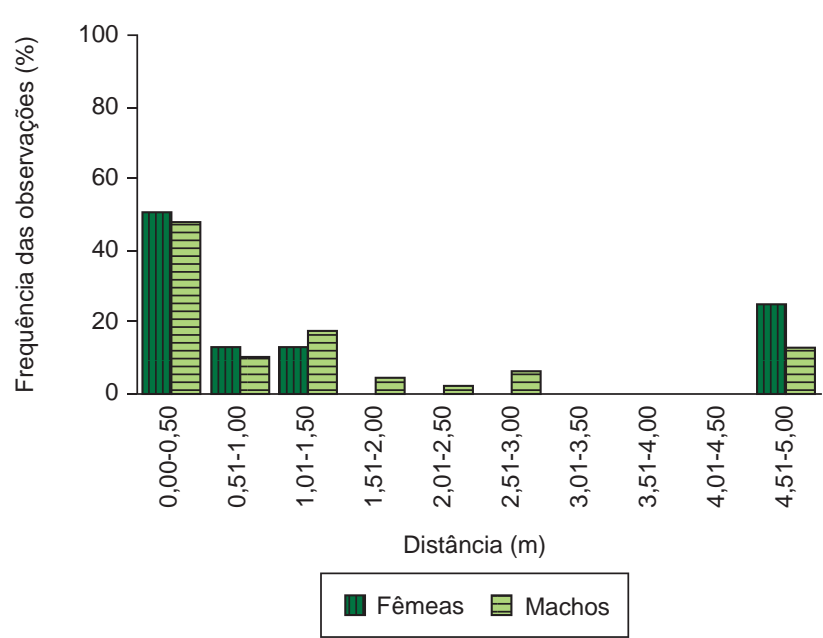

Figura 4. Frequência relativa das observações de machos e fêmeas de Phyllomedusa azurea com relação à distância do corpo dágua mais próximo, no município de Novo Gama, GO, Brasil.

Figure 4. Relative frequency of observations of male and female of Phyllomedusa azurea in relation distance from the nearnest water body from the municipality of Novo Gama, GO, Brazil.

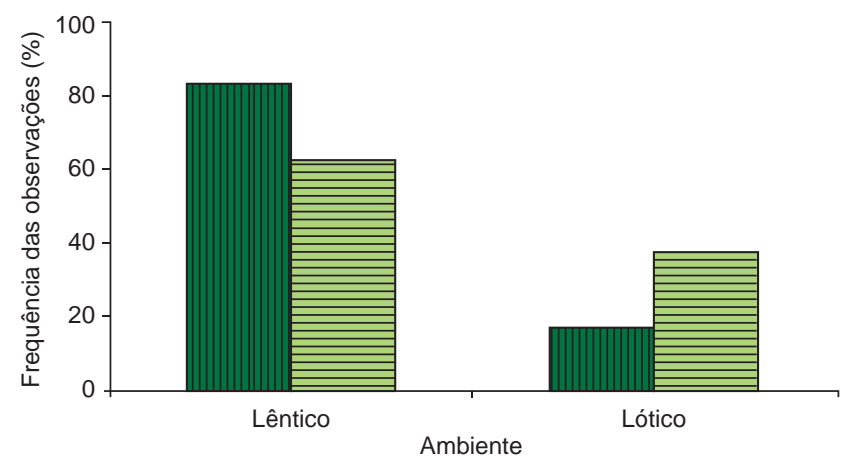

Machos $\boxminus$ Fêmeas

Figura 5. Freqüência relativa das observações de Phyllomedusa azurea com relação à velocidade da água, no município de Novo Gama, GO.

Figure 5. Relative frequency of observations of Phyllomedusa azurea in relation the speed of the water from the municipality of Novo Gama, GO, Brazil.

$B m=4,03$ e $B f=1,80)$. Os machos ingeriram maiores proporções de Araneae (43\%) e as fêmeas de Hymenoptera (67\%) (Tabela 3). $\mathrm{O}$ volume consumido para cada categoria também diferiu entre os sexos (Kolmogorv-Smirnov, $\mathrm{D}_{\max }=0,8788$, g.1. = 2, $\mathrm{P}<0,0001$; $B m=3,92$ e $B f=1,16)$, com os machos consumindo maiores volumes de Araneae (43\%) e as fêmeas de Orthoptera (93\%) (Tabela 3). Os itens mais importantes (IVI) para machos foram Araneae (43\%) e para as fêmeas Orthoptera (63\%) (Tabela 3). Não foi observada relação entre as medidas da cabeça e as dimensões das presas utilizadas por P. azurea (Tabela 4).

Um resumo das condições reprodutivas de machos e fêmeas de Phyllomedusa azurea por classe de tamanho bem como dos volumes dos testículos encontra-se nas Tabelas 5 e 6 . O comprimento rosto 
Freitas, E.B. et al.

Tabela 2. Escores dos cinco primeiros componentes principais das variáveis morfológicas tamanho- ajustadas de machos e fêmeas de Phyllomedusa azurea do município de Novo Gama, GO, Brasil. Valores mais significativos encontram-se em negrito.

Table 2. First five principal component scores for the size-adjusted morphological variables of male and female of Phyllomedusa azurea from Novo Gama, GO, Brazil. Most significant values are in bold.

\begin{tabular}{lccccc}
\hline \multicolumn{1}{c}{ Variáveis } & \multicolumn{5}{c}{ Componentes principais } \\
\cline { 2 - 6 } & $\mathbf{1}$ & $\mathbf{2}$ & $\mathbf{3}$ & $\mathbf{4}$ & $\mathbf{5}$ \\
\hline Altura do corpo & 0,408 & $-0,477$ & $-0,242$ & 0,045 & $-0,447$ \\
Largura do corpo & 0,553 & $-0,237$ & $-0,361$ & 0,301 & 0,108 \\
Altura da cabeça & 0,361 & $-0,425$ & 0,045 & 0,474 & $-0,248$ \\
Largura da cabeça & 0,656 & $-0,330$ & 0,036 & $-0,281$ & $-0,235$ \\
Comprimento da cabeça & $-0,021$ & 0,011 & $-0,697$ & $-0,454$ & 0,133 \\
Diâmetro do tímpano & 0,395 & 0,333 & 0,090 & 0,328 & $-0,206$ \\
Distância interocular & 0,574 & $-0,235$ & $-0,139$ & 0,225 & 0,424 \\
Distância olho-narina & 0,206 & 0,242 & $-0,382$ & $-0,203$ & $-0,045$ \\
Diâmetro do olho & 0,362 & 0,031 & 0,175 & 0,491 & 0,400 \\
Distância internasal & 0,485 & 0,217 & $-0,069$ & 0,060 & $-0,625$ \\
Largura do braço & 0,564 & 0,024 & 0,456 & $-0,217$ & 0,126 \\
Largura do antebraço & 0,743 & $-0,154$ & 0,269 & $-0,295$ & 0,218 \\
Comprimento do braço & 0,291 & 0,391 & $-0,023$ & 0,117 & $-0,267$ \\
Comprimento do antebraço & 0,419 & $-0,014$ & $-0,604$ & 0,285 & 0,177 \\
Comprimento da mão & 0,097 & 0,305 & 0,167 & 0,174 & 0,031 \\
Largura da coxa & 0,593 & $-0,318$ & 0,046 & $-0,383$ & 0,157 \\
Largura da perna & 0,659 & $-0,075$ & 0,315 & $-0,180$ & $-0,078$ \\
Comprimento da coxa & 0,437 & 0,601 & 0,014 & 0,086 & 0,188 \\
Comprimento da perna & 0,520 & 0,447 & $-0,195$ & $-0,129$ & 0,102 \\
Comprimento do pé & 0,388 & 0,617 & $-0,041$ & $-0,151$ & $-0,091$ \\
\hline \multicolumn{7}{c}{ Variância explicada pelos componentes } & & \\
\hline & 4,464 & 2,165 & 1,701 & 1,533 & 1,373 \\
\hline \multicolumn{7}{c}{ Porcentagem de variância explicada } & & 6,865 \\
\hline
\end{tabular}

cloacal (CRC) variou de 32,99 a 41,70 mm em machos e o menor indivíduo reprodutivo apresentou $34,64 \mathrm{~mm}$. Para as fêmeas, o CRC variou de 39,56 a 44,67 $\mathrm{mm}$ e o menor indivíduo reprodutivo apresentou $40,33 \mathrm{~mm}$.

\section{Discussão}

Os espécimes de Phyllomedusa azurea foram observados nos meses com maiores temperatura e umidade relativa do ar, ocupando principalmente as áreas abertas e brejosas com predomínio de vegetação herbácea. Provavelmente a dependência da água por esta espécie seja alta, e os locais escolhidos pelas mesmas, bem como o período no qual são mais avistadas, possam reduzir o risco de dessecação dos adultos bem como dos ovos, que são colocados sobre a vegetação marginal. Fatores como a umidade e a temperatura, são fortemente in uenciados pelos regimes pluviométricos, sendo estes apontados como os principais fatores abióticos que interferem na atividade reprodutiva dos anuros de regiões tropicais (Duellman \& Trueb 1994). A área presentemente estudada apresenta regime sazonal de chuvas, e a maioria das 28 espécies de anuros observadas (dados não publicados), incluindo $P$. azurea, estão reprodutivamente ativas no período de maior precipitação, corroborando com as informações de Haddad \& Sazima (1992) sobre a atividade de anfíbios em ambientes com essas características.
Os machos de $P$. azurea apresentaram padrão reprodutivo prolongado, segundo a classificação de Wells (1977), tendo sido observados vocalizando durante seis meses consecutivos (setembro a fevereiro). Segundo o autor, este padrão é caracterizado ainda pela chegada assincrônica de machos e fêmeas aos sítios reprodutivos. Esse mesmo padrão reprodutivo foi verificado em outras localidades como: Morrinhos, GO (setembro a abril; Borges \& Juliano 2007), Serra da Bodoquena, MS (outubro a maio; Rodrigues et al. 2007), Corumbá, MS (dezembro a março; Ávila \& Ferreira 2004) e Alexânia, GO (setembro a janeiro; Rocha 2005). De modo geral as estratégias reprodutivas em anfíbios anuros derivam de uma combinação de caracteres morfológicos, fisiológicos e comportamentais, adaptados a certas condições ambientais (Pombal 1995).

A atividade noturna de $P$. azurea foi concentrada principalmente no primeiro período da noite, entre as 20:00 e 21:00 h. É possível que as temperaturas nesse período sejam mais favoráveis à atividade de vocalização de algumas espécies, como sugerido por Pombal (1997) para Physalaemus cuvieri e também por De-Carvalho (2008) para Leptodactylus fuscus e Leptodactylus mystacinus. Pombal (1997) acrescenta ainda que as fêmeas aptas à reprodução possam ser beneficiadas se os encontros com os machos ocorrerem no início da noite, pois assim teriam maior tempo para desovar reduzindo as chances de predadores visualmente orientados encontrarem e predarem o casal 

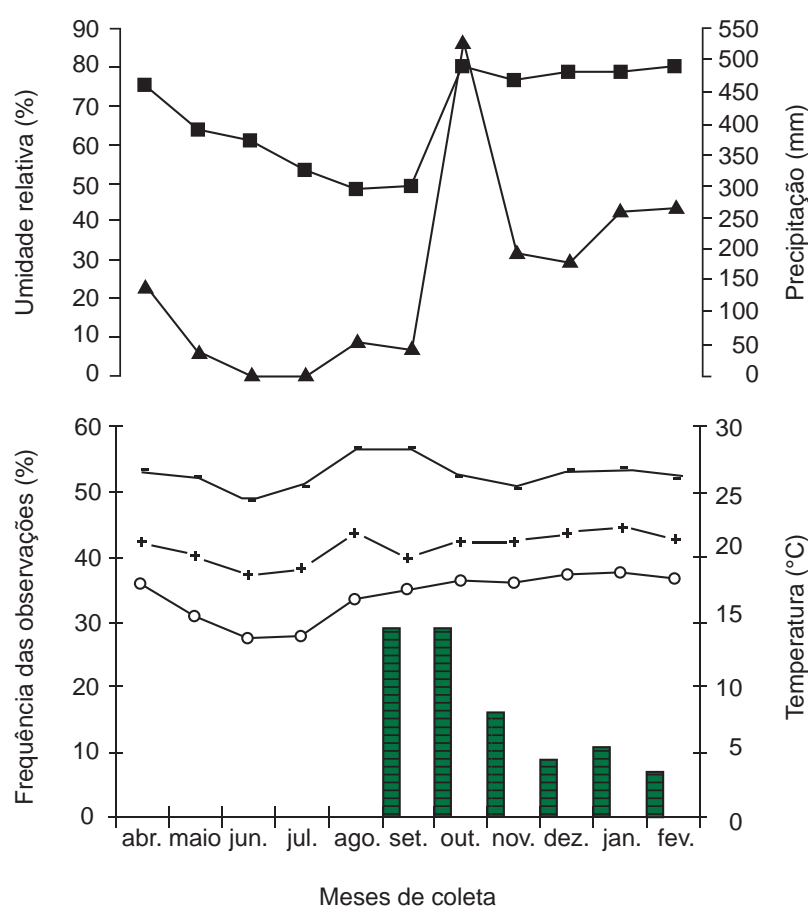

Figura 6. Valores mensais das variáveis climáticas, tomadas na estação meteorológica mais próxima (Brasília) da Fazenda Porta do Céu, Novo Gama, GO entre abril 2006 e fevereiro de 2007. (- $\mathbf{\Delta}$-) precipitação (-ח-) umidade relativa do ar, (-o-) Temperatura mínima (-+-) média, (---) máxima e as barras representam as freqüências relativas mensais de Phyllomedusa azurea.

Figure 6. Monthly values for climatic variables, obtained from the meteorological station (Brasília) nearest to the study site in Novo Gama, GO between April, 2006, and February, 2007: precipitation (- $\mathbf{\Delta}$-); relative humidity (-m-); minimum (---), mean (-) and maximum (- -) temperatures. The bars represent the relative monthly frequencies of Phyllomedusa azurea. em amplexo. A segunda metade da noite muitas vezes corresponde ao período de forrageamento (Haddad 1991) e a queda de temperatura pode também restringir a atividade dos indivíduos (Pombal 1997).

As áreas abertas e brejosas da área estudada formam ambientes relativamente simples com pouca estratificação da vegetação. Nestes locais, arbustos e árvores foram os principais sítios de vocalização utilizados por $P$. azurea. Ambientes como estes, pouco diversificados, restringem o número de possíveis sítios de vocalização e de oviposição. Segundo Rossa-Feres \& Jim (2001) a baixa complexidade estrutural pode constituir um fator limitante na diferenciação dos sítios de vocalização. Provavelmente na área de estudo, ambientes brejosos e com vegetação herbácea sejam os que mais favoreçam a

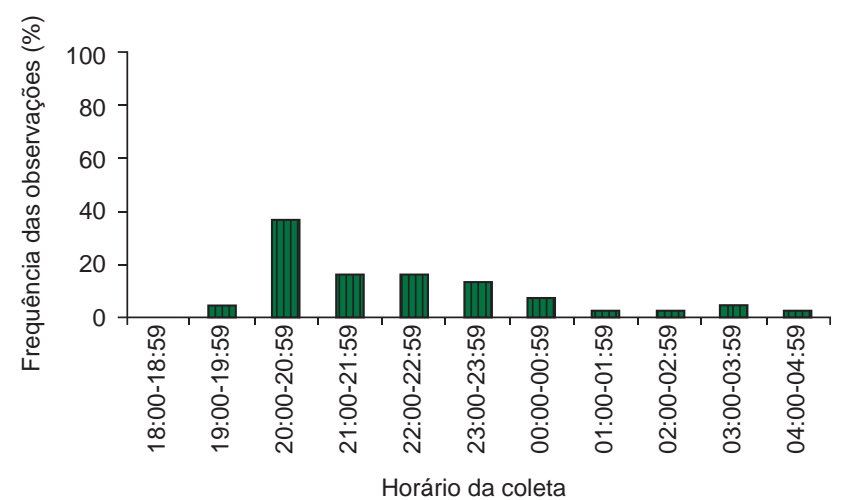

Figure 7. Frequiência relativa do período de atividade de Phyllomedusa azurea do município de Novo Gama, GO, Brasil.

Figure 7. Relative frequency of activity period in Phyllomedusa azurea from the municipality of Novo Gama, GO, Brazil.

Tabela 3. Dieta de machos e fêmeas de Phyllomedusa azurea do município de Novo Gama, GO, Brasil. Freqüência (F) é o número de espécimes contendo um tipo de presa particular, (V) é o volume e $(\mathrm{N})$ o número daquele tipo de presa.

Table 3. Diet of male and female of Phyllomedusa azurea from the municipality of Novo Gama, GO, Brazil. Frequency (F) is the number of specimens containing a particular prey type, $(\mathrm{V})$ is the volume, and $(\mathrm{N})$ is the number of prey type.

\begin{tabular}{|c|c|c|c|c|c|c|c|c|c|c|c|c|c|c|}
\hline \multirow[t]{2}{*}{ Categoria de presas } & \multicolumn{7}{|c|}{ Fêmeas $\mathbf{N}=8$} & \multicolumn{7}{|c|}{ Machos N = 48 } \\
\hline & $\mathbf{N}$ & $\mathrm{N}(\%)$ & $\mathbf{F}$ & $\mathbf{F}(\%)$ & $\mathbf{V}\left(\mathbf{m m}^{3}\right)$ & $\mathrm{V}(\%)$ & IVI & $\mathbf{N}$ & $\mathrm{N}(\%)$ & $\mathbf{F}$ & $\mathbf{F}(\%)$ & $\mathbf{V}\left(\mathbf{m m}^{3}\right)$ & $\mathrm{V}(\%)$ & IVI \\
\hline Araneae & - & - & - & - & - & - & - & 29 & 43 & 20 & 25 & 222,49 & 43 & 43 \\
\hline Blattaria & - & - & - & - & - & - & - & 1 & 1 & 1 & 1 & 91,86 & 18 & 18 \\
\hline Coleoptera & - & - & - & - & - & - & - & 6 & 9 & 6 & 8 & 58,29 & 11 & 10 \\
\hline Crustacea & - & - & - & - & - & - & - & 1 & 1 & 1 & 1 & 25,27 & 5 & 3 \\
\hline Diptera & - & - & - & - & - & - & - & 14 & 21 & 7 & 9 & 0,15 & 0,02 & 10,51 \\
\hline Hemiptera & - & - & - & - & - & - & - & 1 & 1 & 1 & 1 & 52,62 & 10 & 5,5 \\
\hline Hymenoptera & 2 & 67 & 1 & 13 & 2,06 & 7 & 37 & 2 & 3 & 2 & 3 & 2,14 & 0,41 & 1,70 \\
\hline Isoptera & - & - & - & - & - & - & - & 5 & 7 & 2 & 3 & 13,74 & 3 & 5 \\
\hline Lepidoptera & - & - & - & - & - & - & - & 2 & 3 & 2 & 3 & - & - & 1,5 \\
\hline Orthoptera & 1 & 33 & 1 & 13 & 26,36 & 93 & 63 & 6 & 9 & 6 & 8 & 45,75 & 9 & 9 \\
\hline Psocoptera & - & - & - & - & - & - & - & 1 & 1 & 1 & 1 & - & - & 0,5 \\
\hline Material vegetal & - & - & 6 & 75 & - & - & 36 & - & - & 30 & 38 & - & - & - \\
\hline Digestão avançada & - & - & 1 & - & - & - & - & - & - & 3 & - & - & - & - \\
\hline Estômagos vazios & - & - & 2 & - & - & - & - & - & - & 3 & - & - & - & - \\
\hline Total & 3 & - & 8 & - & 28,42 & - & - & 68 & - & 79 & - & 512,32 & - & - \\
\hline B & - & 1,80 & - & - & - & 1,16 & - & - & 4,03 & - & - & - & 3,92 & - \\
\hline
\end{tabular}


Tabela 4. Correlação canônica entre as dimensões das presas e da cabeça de Phyllomedusa azurea do município de Novo Gama, GO, Brasil.

Table 4. Canonical correlation between prey size and head dimensions of Phyllomedusa azurea from the municipality of Novo Gama, GO, Brazil.

\begin{tabular}{|c|c|c|c|}
\hline & \multicolumn{3}{|c|}{ Phyllomedusa azurea $(\mathrm{N}=56)$} \\
\hline & \multicolumn{3}{|c|}{ Coeficientes canônicos } \\
\hline Medidas da cabeça & $\begin{array}{l}1^{a} \text { variável } \\
\text { canônica }\end{array}$ & \multicolumn{2}{|c|}{$\begin{array}{c}2^{\mathrm{a}} \text { variável } \\
\text { canônica }\end{array}$} \\
\hline Comprimento & $-0,80$ & \multicolumn{2}{|c|}{0,59} \\
\hline Largura & 0,46 & \multicolumn{2}{|c|}{0,85} \\
\hline Altura & 0,47 & \multicolumn{2}{|c|}{$-0,10$} \\
\hline \multicolumn{4}{|c|}{ Medidas das presas } \\
\hline Maior comprimento & 0,23 & \multicolumn{2}{|c|}{0,97} \\
\hline Maior largura & 0,74 & \multicolumn{2}{|c|}{0,66} \\
\hline Variáveis canônicas & $\begin{array}{c}\text { Correlação } \\
\text { canônica }\end{array}$ & $\chi^{2}$ & $\mathbf{P}$ \\
\hline I & 0,49 & 10,63 & 0,10 \\
\hline II & 0,39 & 4,05 & 0,13 \\
\hline
\end{tabular}

Tabela 5. Porcentagem de fêmeas de Phyllomedusa azurea coletadas no município de Novo Gama, GO, de diferentes categorias de comprimento rostro-cloacal (CRC) em diferentes estágios reprodutivos, determinados pelo desenvolvimento do oviduto. I - ovidutos desenovelados com tamanhos reduzidos e ovários pouco desenvolvidos, II - os ovidutos estão parcialmente enovelados e os ovários parcialmente desenvolvidos, III - os ovidutos bastante enovelados e ovários bem desenvolvidos.

Table 5. Percentage of female Phyllomedusa azurea from the municipality of Novo Gama, GO relative to the condition of the ovary and oviduct, by snout-vent length (SVL) in different reproductive stages, determined by the development of the oviduct. I - unconvoluted oviduct with reduced sizes and ovaries little developed, II - the oviduct are partly convoluted and ovaries partially developed, III - the oviduct is very convoluted and ovaries very developed.

\begin{tabular}{cccc}
\hline CRC $(\mathbf{m m})$ & I & II & III \\
\hline $39,56-41,26$ & - & - & $2(25,0 \%)$ \\
$41,27-42,97$ & $1(12,5 \%)$ & $2(25,0 \%)$ & - \\
$42,98-44,68$ & - & $2(25,0 \%)$ & $1(12,5 \%)$ \\
\hline
\end{tabular}

Tabela 6. Porcentagem de machos de Phyllomedusa azurea do município de Novo Gama, GO, relacionado à condição do saco vocal, com média (desvio padrão) do volume dos testículos, pelo comprimento rostro-cloacal (CRC). SVR, saco vocal reduzido; SVI, saco vocal intermediário; SVE, saco vocal evidente.

Table 6. Percentage of male Phyllomedusa azurea from the municipality of Novo Gama, GO relative to the condition of the vocal sac, with mean (standard deviation) of testes volume, by snout-vent length (SVL). SVR, reduced vocal sac; SVI, intermediary vocal sac; SVE, evident vocal sac.

\begin{tabular}{ccccccc}
\hline CRC (mm) & \multicolumn{3}{c}{ Estado do saco vocal } & & \multicolumn{2}{c}{ Volume dos testículos (mm $\left.^{3}\right)$} \\
\cline { 2 - 5 } \cline { 5 - 7 } & SVR & SVI & SVE & & $\begin{array}{c}\text { Esquerdo } \\
\text { media } \pm \text { dp }\end{array}$ & $\begin{array}{c}\text { Direito } \\
\text { media } \pm \text { dp }\end{array}$ \\
\hline $32,99-35,89$ & $5(10,4 \%)$ & $14(29,2 \%)$ & $3(6,3 \%)$ & & $1,70 \pm 0,69$ & $2,17 \pm 0,73$ \\
$35,90-38,80$ & $7(14,6 \%)$ & $10(20,8 \%)$ & $2(4,2 \%)$ & & $2,05 \pm 0,79$ & $2,53 \pm 1,29$ \\
$38,81-41,71$ & $2(4,2 \%)$ & $5(10,4 \%)$ & - & $2,29 \pm 0,77$ & $2,20 \pm 1,21$ \\
\hline
\end{tabular}

reprodução e permanência dessa espécie. Trabalhos realizados com Phyllomedusa azurea (ou P. hypochondrialis antes da revalidação para as áreas de Cerrado do Brasil Central e de in uência do Pantanal por Caramaschi 2006) relatam a presença dessa espécie em locais com características semelhantes às presentemente registradas e/ou utilizando substratos similares (Bastos et al. 2003, Ávila \& Ferreira 2004, Borges \& Juliano 2007, Rodrigues et al. 2007). Outras espécies do gênero Phyllomedusa são também comumente encontradas nestas condições como P. tetraploidea (Bernarde \& Anjos 1999), P. distincta (Pombal 1997) e P. tomopterna (Bernarde et al. 1999).

Características morfológicas e comportamentais de $P$. azurea podem também contribuir para a escolha de determinados sítios dentre outros disponíveis na área. Segundo Caramaschi (1981) a utilização de determinados substratos pode ser limitada pela morfologia e tamanho das espécies. Phyllomedusa azurea bem como outras espécies do gênero possuem alguns de seus dedos oponíveis (Caramaschi 2006), adaptação essa que possibilita a utilização de galhos finos como poleiros.

A preferência por substratos arbóreos e arbustivos verificados para $P$. azurea na área estudada está também relacionada ao modo reprodutivo, que envolve a deposição de ovos sobre a vegetação marginal de corpos d'água, onde ocorre o início do desenvolvimento dos embriões. Segundo Zug et al. (2001) os representantes do gênero Phyllomedusa depositam em torno de 100 a 150 ovos em folhas e ramos pendentes sobre a água, com os girinos aí formados terminando seu desenvolvimento nos corpos d’água.

A ocorrência de ovos e girinos de $P$. azurea em ambientes distintos pode expor os indivíduos em desenvolvimento a diferentes tipos de predadores. Na área estudada foi observada a predação de um ninho desta espécie por percevejo. Segundo Duellman \& Trueb (1994) ovos que são colocados suspensos na vegetação acabam ficando expostos a predadores que normalmente não ocorrem na água, servindo como fonte de energia de alto teor protéico para muitos predadores. Em estudo realizado com Phyllomedusa tarsius, P. tomopterna e P. bicolor, foi verificado que os principais predadores de ovos dessas espécies são besouros, moscas e mamíferos (Neckel-Oliveira \& Wachlevski 2004). Já nos ambientes aquáticos peixes, larvas de libélulas, aranhas e baratas d'água podem representar predadores dos girinos e as vezes de adultos dos anfíbios (Hero et al. 2001, Toledo 2003, 2005, Menin et al. 2005, Sawaya et al. 2008).

Além de substratos para a postura de ovos, arbustos e árvores foram utilizados por Phyllomedusa azurea como sítios de vocalização semelhante ao observado para esta espécie por Rodrigues et al. (2007) na Serra da Bodoquena, MS, por Borges \& Juliano (2007) em Morrinhos, GO e por Rocha (2005) em Alexânia, GO. Este último autor relata inclusive a presença de machos de $P$. azurea vocalizando em alturas de até 2,5 m, semelhante aos registros obtidos para alguns machos no presente trabalho.

Nenhum tipo de relação foi verificado entre o tamanho da cabeça e o das presas consumidas por $P$. azurea, embora a capacidade de abertura da boca e o tamanho do corpo já tenham sido apontados por Strussman et al. (1984) como importantes na seleção de tamanhos adequados de presas. Tradicionalmente os anuros são descritos como predadores generalistas, com comportamento oportunista de forrageamento (Duellman \& Trueb 1994), sendo suas dietas constituídas predominantemente de artrópodes e re etindo a relativa abundância de presas no ambiente (Hirai \& Matsui 1999). Representantes do gênero Phyllomedusa utilizam estratégias do tipo "senta-e-espera", como relatado para P. burmeisteri (Bertoluci 2002). 
Phyllomedusa azurea teve sua dieta constituída por onze itens alimentares, incluindo artrópodes e material vegetal, apontando para um provável padrão generalista. Porém ao se analisar separadamente os sexos, as fêmeas tiveram sua dieta bem restrita, tendo Orthoptera como o principal item. Provavelmente esse recurso, dentre todas as categorias de presas consumidas por $P$. azurea, forneça maior retorno energético para as fêmeas, porém o número de estômagos analisados para indivíduos deste sexo impossibilita generalizações. Com relação à ingestão de material vegetal, Anderson \& Marthis (1999) sugerem que a mesma acontece de forma acidental quando há captura de presas sobre o substrato, mas que esse material contribuiria com uma parcela nutricional na dieta e serviria ainda como fonte extra de absorção de água pelo organismo para prevenir a dessecação. Já Santos et al. (2004) sugerem que o material vegetal poderia ser ingerido ativamente pelos anuros de forma a auxiliar na eliminação de parasitas intestinais e exoesqueletos de invertebrados.

Alguns indivíduos machos foram encontrados com os estômagos vazios, o que pode estar relacionado com a reprodução (Van Sluys \& Rocha 1998). É conhecido na literatura que muitos machos de anuros podem permanecer em jejum durante o período reprodutivo, já que os mesmos passariam um período prolongado vocalizando em sítios diferentes daqueles utilizados para forrageamento (Duellman \& Trueb 1994).

A espécie é dimórfica com fêmeas maiores e mais pesadas que os machos, fato este provavelmente relacionado a um investimento diferenciado na reprodução entre os sexos. O maior tamanho das fêmeas em relação aos machos corrobora com os resultados obtidos para a mesma e para outras espécies do gênero ( $P$. sauvagii e $P$. oreades) em áreas de Cerrado (Brandão 2002, Rodrigues et al. 2007). De acordo com Shine (1979) e Zug et al. (2001) o dimorfismo sexual em anuros é comum, sendo as fêmeas em geral maiores que os machos, podendo apresentar também diferenças em relação a coloração e a características morfológicas. Maior tamanho em fêmeas é em geral associado com a produção de ovos e fecundidade das mesmas (Crump 1974, Woolbright 1989). Com relação aos machos, se considerado o baixo custo investido para a produção de espermatozóides, um indivíduo pode ter pequeno porte e mesmo assim produzir uma grande quantidade de gametas. $\mathrm{O}$ tamanho dos machos em espécies que apresentam reprodução de período prolongado, como verificado na espécie deste estudo, pode também ser afetado pelos gastos energéticos com a vocalização, defesa do território e diferenças na dieta (Woolbright 1982).

A população de Phyllomedusa azurea estudada apresentou atividade restrita aos meses de maior precipitação e umidade, padrão normalmente observado em espécies do Cerrado. Segundo Brites et al. (in press) neste bioma, os eventos reprodutivos tendem a ocorrer em épocas mais restritas do ano, normalmente nos meses mais quentes e chuvosos quando há a formação de ambientes temporários favoráveis ao desenvolvimento dos girinos. O padrão reprodutivo foi do tipo prolongado estendendo-se por vários meses. Como em outras espécies do gênero, $P$. azurea foi mais freqüente em locais próximos a corpos d'água de ambientes abertos e brejosos (e.g., P. oreades, $P$. sauvagii) (Brandão 2002, Rodrigues et al. 2007), sendo normalmente encontrada vocalizando sobre arbustos. Esses locais constituíram os principais sítios de vocalização e deposição de ovos de $P$. azurea, e são também utilizados por outros representantes do grupo de $P$. hypochondrialis (Caramaschi 2006). Ambientes como os anteriormente citados favorecem o comportamento reprodutivo do grupo, que inclui a postura de ovos em ninhos construídos enrolando ou unindo uma ou mais folhas, que ficam suspensos sobre os corpos d'água (Cruz 1982, Caramaschi \& Cruz 2002). Ao eclodirem os girinos completam seu desenvolvimento na água (Bastos et al. 2003). Dessa forma a escolha de substratos adequados sobre os corpos d'água é de extrema importância para o sucesso reprodutivo dessa espécie.

\section{Agradecimentos}

Agradecemos aos senhores Enrique Sevilla e Geraldo Barbosa por terem cedido a área da fazenda Porta do Céu para realização deste trabalho. A todos os colegas que auxiliaram em campo e em laboratório. Ao amigo Daniel Oliveira Santana pela elaboração da ilustração utilizada no trabalho. Aos professores Dr. Daniel Oliveira Mesquita e Dr. Stephen Francis Ferrari e ao amigo Dr. Frederico Gustavo França pelas críticas e revisão do texto. Ao IBAMA pela concessão da licença n ${ }^{\circ}$ 02010.000583/2006-89. As Faculdades Integradas da Terra de Brasília por ter cedido o laboratório e equipamentos necessários à triagem do material.

\section{Referências Bibliográficas}

AYRES, M., AYRES Jr., M., AYRES, D.L. \& SANTOS A.A. 2007. Bioestat 5.0. USP, São Paulo.

ANDERSON, M.T. \& MARTHIS, A. 1999. Diets of two sympatric neotropical salamanders, Bolitoglossa mexicana and B. rufescens, with notes on reproduction for B. rufescens. J. Herpetol. 33(4):601-607.

ÁVILA, R.W. \& FERREIRA, V.L. 2004. Richness of species and density of vocalization of anurans in an urban area of Corumbá, Mato Grosso do Sul, Brazil. Rev. Bras. Zool. 21(4):887-892.

BASTOS, R.P., MOTTA, J.A.O., LIMA, L.P. \& GUIMARÃES, L.D. 2003. Anfíbios da Floresta Nacional de Silvânia de Goiás. Stylo Gráfica e Editora, Goiânia.

BERNARDE, P.S. \& ANJOS, L. 1999. Distribuição espacial e temporal da anurofauna no Parque Estadual Mata dos Godoy, Londrina, Paraná, Brasil (Amphibia: Anura). Com. Mus. Cienc. PUCRS, Sér. Zool. 12:127-140.

BERNARDE, P.S., KOKUBUM, M.C.N., MACHADO, R.A. \& ANJOS, L. 1999. Uso de habitats naturais e antrópicos pelos anuros em uma localidade no Estado de Rondônia, Brasil (Amphibia: Anura). Acta Amazônica 29(4):555-562.

BERTOLUCI, J. 2002. Pedal luring in the leaf-frog Phyllomedusa burmeisteri (Anura, Hylidae, Phyllomedusinae). Phyllomedusa 1(2):93-95.

BORGES, F.J.A. \& JULIANO, R.F. 2007. Distribuição espacial e temporal de uma comunidade de anuros do município de Morrinhos, Goiás, Brasil (Amphibia: Anura). Neotrop. Biol. Conserv. 2(1):21-27.

BRITES, V.L.C., FARIA, R.G., MESQUITA, D.O. \& COLLI, G.R. (in press). The herpetofauna of the Neotropical Savannas. In Unesco-Eolss. (Org.). Encyclopedia of Life Support Systems - Theme in Tropical Biology and Natural Resources. Unesco-Eolss, Paris.

BRANDÃO, A.R. 2002. A new specie of Phyllomedusa Wagler, 1830 (Anura: Hylidae) from Central Brazil. J. Herpetol. 36(4):571-578

BUZZI, Z.J. 2002. Entomologia Didática. 4 ed. Editora UFPR, Curitiba.

CARAMASCHI, U. 1981. Variação estacional, distribuição espacial e alimentação de populações de Hylideos na represa do Rio Pardo (Botucatu) (Amphibia, Anura, Hylidae). Dissertação de Mestrado, Instituto de Biologia da Universidade Estadual de Campinas, Campinas.

CARAMASCHI, U. 2006. Redefinição do grupo de Phyllomedusa hypochondrialis, com redescrição de P. megacephala (Miranda-Ribeiro, 1926), revalidação de $P$. azurea Cope, 1862 e descrição de uma nova espécie (Amphibia, Anura, Hylidae). Arq. Mus. Nac. Rio de Janeiro 64(2):159-179.

CARAMASCHI, U. \& CRUZ, C.A.G. 2002. Phyllomedusa posição taxonômica, hábitos e biologia (Amphibia, Anura, Hylidae). Phyllomedusa 1(1):5-10.

CRUMP, M.L. 1974. Reproductive strategies in a tropical anuran community. Misc. Publs Mus. Nat. Hist. Univ. Kans., Lawrence, (61):1-68.

CRUMP, M.L. \& SCOTT, N.J.J. 1994. Visual encounter surveys. In Measuring end monitoring biological diversity: standart methods for amphibians. 
(Heyer, W.R., Donelly, M.A., McDiarmid, R.W., Hayek. L.C. \& Foster, M.S., eds.). Smithsonian Institute Press, Washington, p. 84-92.

CRUZ, C.A.G. 1982. Conceituação de grupo de espécies de Phyllomedusinae brasileiras com base em caracteres larvários (Amphibia, Anura, Hylidae). Arquivos da Universidade Federal Rural do Rio de Janeiro 5:147-171.

DE-CARVALHO, C.B., FREITAS, E.B., FARIA, R.G., BATISTA, R.C. BATISTA, C.C, COELHO, W.A. \& BOCCHIGLIERI, A. 2008. Natural history of Leptodactylus mystacinus and Leptodactylus fuscus (Anura: Leptodactylidae) in the Cerrado of Central Brazil. Biota Neotrop. 8:(3) http://www.biotaneotropica.org.br/v8n3/en/ abstract?article+bn01308032008 (último acesso em 04 outubro 2008)

DUELLMAN, W.E. \& TRUEB, L. 1994. Biology of Amphibians. Ed. Johns Hopkins, New York.

DURE, M.I. 1999. Phyllomedusa hypocondrialis. Diet. Herpetol. Rev. 30(2):92.

EITEN, G. 1972. The Cerrado vegetation of Brazil. Bot. Rev. 38(2):201-341.

ETEROVICK, P.C. \& SAZIMA, I. 2004. Anfíbios da Serra do Cipó. Ed. PUC Minas, Belo Horizonte.

FROST, D.R. 2008. Amphibians Species of The Wolrd 5.1 - an online reference. American Museum of Natural History. http://research.amnh. org/herpetology/amphibia/index.php (último acesso em 21 outubro 2008).

GADSDEN, H.E. \& PALACIOS-ORONA, L.E. 1997. Seasonal Dietary Patterns of the Mexican fringe-toed Lizard (Uma paraphygas). J. Herpetol. 31(1):1-9.

HADDAD, C.F.B. 1991. Ecologia reprodutiva de uma comunidade de anfíbios anuros da Serra do Japi, Sudeste do Brasil. Tese de Doutorado, Universidade Estadual de Campinas, São Paulo.

HADDAD, C.F.B. \& SAZIMA, I. 1992. Anfíbios anuros da Serra do Japi. In História natural da Serra do Japi: ecologia e preservação de uma área orestal no Sudeste do Brasil. (L.P.C. Morellato, org.). 1ª ed. UNICAMP/ FAPESP, São Paulo, p. 188-211.

HERO, J.M., MAGNUSSON, W.E., ROCHA, C.F.D. \& CATTERALL, C.P. 2001 Antipredator defenses in uence the distribution of amphibian prey species in the central Amazon rainforest. Biotropica 33(1):131-141

HIRAI, T. \& MATSUI, M. 1999. Feeding habits of the pond frog, Rana nigromaculata, inhabiting rice fields in Kyoto, Japan. Copeia 1999(4):940-947.

HILL, P. \& LEWICKI, T. 2007. Statistics Methods and Applications. StatSoft, Tulsa, Oklahoma.

LUCAS, E.M., BRASILEIRO, C.A., OYAMAGUCHI, H.M. \& MARTINS, M. 2008. The reproductive ecology of Leptodactylus fuscus (Anura, Leptodactylidae): new data from natural temporary ponds in the Brazilian Cerrado and a review throughout its distribution. J. Nat. Hist. 42(35-36):2305-2320.

MENIN, M., RODRIGUES, D.J. \& AZEVEDO, C.S. 2005. Predation on amphibians by spiders (Arachnida, Araneae) in the Neotropical region. Phyllomedusa 4(1):39-47.

MAGNUSSON, W.E., LIMA, P.A., SILVA, W.A. \& ARAÚJO, M.C. 2003. Use of geometric forms to estimate volume of invertebrates in ecological studies of dietary overlap. Copeia 2003(1):13-19.

MESQUITA, D.O., COSTA, G.C. \& ZATZ, M.G. 2004. Ecological aspects of the casque-headed frog Aparasphenodon brunoii (Anura, Hylidae) in a Restinga habitat in southeastern Brasil. Phyllomedusa 3(1):51-59.

NECKEL-OLIVEIRA, S. \& WACHLEVSKI, M. 2004. Predation on the arboreal eggs of three species of Phyllomedusa in Central Amazonian. J. Herpetol. 38(2):244-248.

NIMER, E. 1989. Climatologia do Brasil. 2 ed. IBGE, Departamento de Recursos Naturais e Estudos Ambientais, Rio de Janeiro.

POMBAL Jr., J.P. 1995. Biologia reprodutiva da anuros (Amphibia) associados a uma poça permanente na Serra da Paranapiacaba, sudeste do Brasil. Rio Claro. Tese de Doutorado, Instituto de Biociências, Universidade Estadual Paulista, São Paulo.

POMBAL Jr., J.P. 1997. Distribuição espacial e temporal de anuros (Amphibia) em uma poça permanente na Serra de Paranapiacaba, sudeste do Brasil. Rev. Bras. Biol. = Bras. J. Biol. 57(4): 583-594.
POUGH, F.H., ANDREWS, R.H., CADLE, J.E, CRUMP, M.L., SAVITZKY, A.H. \& WELLS, K.D. 2004. Herpetology. 3 ed. Pearson Pretince Hall, Upper Saddle River, New Jersey.):55-56.

ROCHA, E.B. 2005. Aspectos ecológicos de Phyllomedusa hypochondrialis em uma área de Cerrado do Brasil Central. Monografia, Faculdades Integradas da Terra de Brasília, Distrito Federal.

RODRIGUES, D.J., LOPES, F.S \& UETANABARO, M. 2003. Padrão reprodutivo de Elachistocleis bicolor (Anura, Microhylidae) na Serra da Bodoquena, Mato Grosso do Sul, Brasil. Iheringia, Sér. Zool. 93(4):365-371.

RODRIGUES, D.J., UETANABARO, M. \& LOPES, F.S. 2005. Reproductive patterns of Trachicephalus venulosus (Laurenti, 1768) and Scinax fuscovarius (Lutz, 1925) from the Cerrado, Central Brazil. J. Nat. Hist. 39(35):3217-3226.

RODRIGUES, D.J., UETANABARO, M. \& LOPES, F.S. 2007. Breeding biology of Phyllomedusa azurea Cope, 1862 and P. sauvagii Boulenger, 1882 (Anura) from the Cerrado, Central Brazil. J. Nat. Hist. 41(29-32):1841-1851.

ROSSA-FERES, D.C. \& JIM, J. 2001. Similaridade do sítio de vocalização em uma comunidade de anfíbios anuros na região noroeste do estado de São Paulo, Brasil. Rev. Bras. Biol. = Bras. J. Biol. 18(2):439-454.

SANTOS, E.M., ALMEIDA, A.V. \& VASCONCELOS, S. 2004. Feeding habits of six anuran (Amphibia: anura) species in a rainforest fragment in northeaster Brazil. Ilheringa, Sér. Zool. 94(4):433-438.

SAWAYA, R.J., MARQUES, O.A.V. \& MARTINS, M. 2008. Composição e história natural das serpentes de Cerrado de Itirapina, São Paulo, sudeste do Brasil. Biota Neotrop. 8(2): http://www.biotaneotropica.org.br/v8n2/pt/ abstract?article+bn01308022008 (último acesso em 06 outubro 2008).

SHINE, R. 1979. Sexual selection and sexual dimorphism in the Amphibia. Copeia 1979(2):297-306

SILVA, W.R., GIARETTA, A.A. \& FACURE, K.G. 2005. On the natural history of the South American pepper frog, Leptodactylus labyrinthicus (Spix, 1824) (Anura: Leptodactylidae). J. Nat. Hist. 39(7):555-566.

SIMPSON, E.H. 1949. Measurement of diversity. Nature 163:1-688.

STRÜSSMANN, C., VALE, M.B.R.D., MENEGHINI, M.H. \& MAGNUSSON, W.E. 1984. Diet and foranging mode of Bufo marinus and Leptodactylus ocellatus. J. Herpetol. 18(2):138-146.

TABACHNICK, B.G. \& FIDELL, L.S. 2000. Using multivariate statistics. 4 ed. Allyn \& Bacon, New York.

TOLEDO, L.F. 2003. Predation on seven South American anuran species by water bugs (Belostomatidae). Phyllomedusa 2(2):105-108.

TOLEDO, L.F. 2005. Predation of juvenile and adult anurans by invertebrates: current knowledge and perspectives. Herpetol. Rev. 36(4):395-400.

VAN SLUYS, M. \& ROCHA, C.F.D. 1998. Feeding habitats an microhabitats utilization by two syntopic Brazilian Amazonian frogs Hyla minuta and Pseudopaludicula sp. (gr. falcipes). Rev. Bras. Biol. = Bras. J. Biol. 58(4):559-562.

ZAR, J.H. 1999. Biostatistical Analysis. 2 ed. Prentice-Hall, Inc., Upper Saddle River, New Jersey.

ZUG, G.R., VITT, L.J. \& CALDWELL, J.P. 2001. Herpetology: an introductory biology of amphibians and reptiles. 2 ed. Academic Press, San Diego.

WELLS, K.D. 1977. The social behavior of anuran amphibians. Anim. Behav. 25(3):666-693.

WILKINSON, L. 1990. SYSTAT: The System for Statistics. Systat Inc., Evanston, Illinois.

WOOLBRIGHT, L.L. 1982. Sexual selection and size dimorphism in anuran amphibia. Am. Nat. 121(1):115-199.

WOOLBRIGHT, L.L. 1989. Sexual dimorphism in Eleutherodactylus coqui: selection pressures and growth rates. Herpetologica 45(1):68-74.

Recebido em 20/07/08 Versão reformulada recebida em 01/12/08 Publicado em 02/12/08 